\title{
Armadilha das pirâmides
}

\author{
The pyramid trap
}

Erno Harzheim 1

Carlos Álvarez-Dardet 1

\footnotetext{
1 Departamento de Salud Pública, Universidad de Alicante. Ed. Ciencias Sociales, Campus San Vicent del Raspeig, A. P. 99, Alicante 03080, España. carlos.alvarez@ua.es
}

\begin{abstract}
This paper discusses the impact of globalization on public health practice. Neoliberal supremacy has resulted in both greater interdependence between countries and increasing inequalities. Globalization of health risks and the dependence of local health conditions on external forces precludes the use of local/national solutions for global problems. In this context, the classical organization of public health services in a hierarchical pyramid based on geographically defined areas (from the local to the regional and national levels) no longer makes sense. We thus suggest some characteristics of a different type of organization based on new information technologies: a transnational network, horizontally shaped, more independent from political power, allowing for exchange of information and good practices, promoting dissemination of knowledge and producing "glocal" solutions. Through the creation of work opportunities between health professionals, the model will permit the creation of common strategies and increase the power of their political demands, perhaps allowing for the collective development of a more equitable world.
\end{abstract}

Key words Health Policy; Public Health Practice; Public Policy

Resumo Neste artigo, abordamos as repercussões do processo de globalização sobre a prática de saúde pública. A supremacia do neoliberalismo vem causando crescente interdependência entre os países e aumento das desigualdades, exigindo transformação da prática sanitária. A globalização de riscos e a dependência dos determinantes de saúde locais a fatores externos, impedem a busca de soluções nacionais/locais de maior eficácia frente a problemas de origem global. Neste contexto, as instituições atuais de saúde pública, historicamente piramidais e dependentes do poder político estatal, centradas na análise e ação distrital, carecem das características necessárias para estimular essa transformação. Assim, sugerimos a adoção de uma nova prática embasada no uso das novas tecnologias de informação. Uma rede internacional de profissionais de saúde, horizontalizada, mais independente frente ao poder político estatal, que possibilite a troca de informações e modelos de boa prática, socializando o conhecimento e "glocalizando" soluções. Ao favorecer o trabalho entre pares permitirá estratégias conjuntas e fortalecimento das demandas políticas, possibilitando, talvez, a construção de um mundo com mais eqüidade.

Palavras-chave Política de Saúde; Prática de Saúde Pública; Política Social 


\section{Introdução}

As transformações na velocidade dos fluxos de capitais, mercadorias, informação e indivíduos entre os países, com suas profundas repercussões no nível econômico, político, social e cultural, denominadas em conjunto como globalização, vêm suscitando um intenso debate no campo da saúde pública. Este tem se polarizado entre dois grupos que se centram nos aspectos negativos ou positivos da mesma sobre a saúde da população, propondo estratégias diferentes na forma como o setor público deve enfrentar estas transformações. Nos parece interessante que neste debate, direcionado principalmente às políticas públicas, está ausente uma maior preocupação com a prática de saúde pública que esta nova situação nos exige. Por quê a prática dos profissionais de saúde não ocupa lugar de destaque, surgindo como exemplo de ação concreta contra as desigualdades? Onde estão estes profissionais que deveriam ser protagonistas frente aos esforços organizados da sociedade em busca da promoção da saúde, do bem-estar e da eqüidade?

Permanecem presos às clássicas estruturas piramidais de saúde pública de cada Estadonação, verticalizadas, estabelecidas sobre uma área geográfica definida e com capacidade de decisão subordinada às estruturas políticas estatais. Considerando a complexidade do processo de mudança que vivemos, tanto a globalização, como a crescente interdependência, desafiam claramente o controle nacional das políticas sanitárias (Walt, 1998). A busca de soluções nacionais e locais para problemas globais, principalmente a pressão de poderosos grupos econômicos sobre os sistemas de saúde universalizantes de países ricos e pobres, não mostrará senão soluções parciais. Neste contexto de globalização de riscos e doenças, da dependência dos determinantes locais de saúde a fatores externos, de preponderância da moeda sobre o ser humano, sugerimos uma alternativa para a prática dos profissionais de saúde pública. Uma nova forma de atuação em nível internacional e local que faça frente aos desafios e ameaças originados da globalização e utilizando as oportunidades criadas por esta, possa lutar com maior poder de ação e decisão na busca de melhores condições de vida e saúde para a população do planeta. Neste artigo, descrevemos os principais aspectos que caracterizam o novo cenário mundial, as características que desabilitam as instituições atuais de saúde pública a lidar de maneira eficaz com este cenário e, ao final, apontaremos as características básicas de uma proposta para uma no- va estrutura organizativa para a prática de saúde pública.

\section{Situação global}

Como demonstra o Human Development Report, o abismo entre ricos e pobres vem crescendo acompanhando o ritmo de crescimento do intercâmbio de capitais, bens e serviços. Em 1960 , a razão entre a renda dos $20 \%$ mais ricos em relação a dos $20 \%$ mais pobres era de $30: 1$, em 1990 era de 60:1 e em 1997 de 74:1. Estes $20 \%$ mais ricos detêm cerca de $86 \%$ do Produto Interno Bruto (PIB) mundial em comparação com $1 \%$ dos $20 \%$ mais pobres (UNDP, 1999). Conhecendo a relação entre saúde e desigualdade, não nos parece estranho que os níveis de saúde e bem-estar estejam estagnados e inclusive piorando em muitas regiões do mundo (Wilkinson, 1996). Lang \& Caraher (no prelo) nos apontam outras conseqüências da globalização sobre o processo saúde-doença, que tornam inexorável a necessidade de ações de saúde pública coordenadas em nível internacional, em uma espécie de governo global de saúde pública. A primeira destas conseqüências é derivada do fluxo aumentado de pessoas e mercadorias, que serve como propagador de doenças infecciosas e também de resistência microbiológica, não respeitando as "barreiras alfandegárias". A epidemia de AIDS ilustra este fenômeno, ao provocar o ressurgimento da tuberculose em países desenvolvidos e dificultar seu controle em países em desenvolvimento, devido ao aumento de casos por cepas com maior resistência farmacológica, tanto em indivíduos HIV positivos como negativos. Paralelamente, as patologias não-comunicáveis tão pouco respeitam as fronteiras nacionais e, através de formas e mecanismos distintos, como mudanças no estilo de vida e padrões sociais, pressões econômicas e danos a frágeis economias locais, mudam o perfil epidemiológico dos países em desenvolvimento, fazendo coexistir lado a lado, a hipercolesterolemia e a febre amarela, a desnutrição e a anorexia nervosa, doenças originadas da carência e da abundância. A terceira conseqüência é o aumento das viagens nacionais e internacionais, reforçando o risco de disseminação de doenças infecciosas e também aumentando os níveis de poluição, que contribuem para a instabilidade climática. A quarta é o fluxo crescente de bens e mercadorias, devido a eliminação de barreiras alfandegárias através da Organização Mundial do Comércio (OMC) que exemplificado pelo comércio de alimentos gera a ruína de eco- 
nomias locais, como também conseqüências adversas originadas do trânsito dos mesmos, tanto em seu controle sanitário, como em repercussões econômicas e ecológicas associadas, demonstradas pelas crises das vacas loucas e da febre aftosa na Europa. Por último, as instituições de saúde pública nacionais sem poder de ação em nível internacional, num mundo da supremacia do mercado livre, só tem voz nas conseqüências sanitárias da globalização num momento de crise, principalmente se ela afeta os países ricos. Podemos afirmar que aproximadamente $40 \%$ das causas de morte no Brasil no ano de 1998, representadas entre outras, pela AIDS, doenças cárdio-vasculares e neoplasia de pulmão, têm implicações causais direta ou indiretamente relacionadas à globalização (DATASUS, 2001).

Se o momento atual impõe à saúde pública e à prática da medicina a necessidade de pensar e agir internacionalmente, mesmo frente a problemas locais, por que se necessita uma nova forma de atuação? No cenário internacional já não contamos com agências intergovernamentais que objetivam melhorar o padrão de saúde, inclusive saúde para todos? Nossa resposta é que estas agências apresentam as mesmas características piramidais das estruturas de saúde pública dos estados nacionais e, como eles, sofrem, quando não exercem pressões semelhantes tanto de origem econômica, como política. Agências internacionais ligadas à Organização das Nações Unidas (ONU), como a Organização Mundial da Saúde (OMS), o Fundo das Nações Unidas para a Infância (UNICEF), o Banco Mundial e a OMC vêm recebendo críticas devido a sua própria estrutura organizativa e também ao seu posicionamento (a) político (Lee et al., 1996; Navarro, 1997). Suas rígidas estruturas organizativas, verticalizadas, definem estratégias em ambientes muito afastados das origens concretas dos problemas e com limitada capacidade de aplicação nos países-alvo. Somado a isto, suas estruturas decisórias e necessidades de financiamento as fazem suscetíveis a pressões políticas, como a que exerce os Estados Unidos, impedindo uma atuação crítica frente a políticas econômicas internacionais francamente deletérias à saúde da população. Por quê as decisões da OMC atingem prerrogativas legais entre os países enquanto as diversas convenções e acordos internacionais acerca da saúde pública, não? Será por quê as organizações de natureza econômica e defensoras do capital mundial estão sentadas à mesa das decisões em saúde pública, enquanto a relação inversa não existe? Quando se reunirão os ministros de saúde, de educação e meio-ambiente de todo o mundo junto aos responsáveis pela economia para tomar decisões acerca do comércio internacional que afetam a saúde e o meio-ambiente?

Por outro lado, presenciamos o surgimento de novos atores no cenário da saúde internacional, não tão poderosos quanto a OMC ou o Banco Mundial, mas com grande poder de influência, formados pelas organizações nãogovernamentais e as de ação direta (McKee et al., 2001). Com estrutura menos rígida, mais horizontalizada e próxima à realidade em que atuam, vêm enriquecendo o debate sobre as repercussões da globalização na saúde, defendendo novas estratégias de ação. Sendo mais independentes, política e economicamente, fazem uma crítica mais aberta ao capital internacional e à idéia de inexorabilidade da globalização neoliberal, entendendo a globalização como uma nova relação de forças (Laurell, 2000). Junto à sociedade civil, nos proporcionaram os primeiros movimentos de contestação à hegemonia neoliberal através das manifestações em Seattle e Praga. Em dezembro de 2000, em Bangladesh, unidos a People's Health Assembly redigem a People's Chart for Health, definindo ações internacionais necessárias ao combate às desigualdades em saúde, com potencial de sobrepor-se à importância da Declaração de Alma-Ata (Baum, no prelo). E, há poucos meses, unidos a sindicatos e a um governo municipal e estadual comprometidos com a realidade social, realizaram o Fórum Social Mundial em Porto Alegre, numa tentativa de apresentar novos caminhos para o desenvolvimento mundial, com eqüidade e justiça social. Com suas ações e sua representatividade popular, as organizações não-governamentais têm aumentado sua influência no cenário internacional, nos estimulando a propor uma nova forma de ação para a saúde pública e a medicina em nível mundial.

\section{A prática prisioneira de saúde pública}

Estas transformações e desafios que o mundo globalizado nos apresenta nos dias de hoje, expõem a fragilidade e falta de eficácia dos serviços nacionais de saúde pública, originários do modelo de Estado-nação do século XIX. Classicamente organizados de maneira piramidal, baseados sobre uma área geográfica definida, hierarquizados em níveis locais, regionais e nacionais, com um vértice decisório burocrático, formam uma estrutura incapaz de lidar com a crescente globalização dos riscos e doenças. Suas origens se remontam ao tempo em que os 
distritos, o território, eram a base política, econômica e cultural das sociedades. O fluxo de mercadorias e pessoas era mínimo e praticamente todas as condições materiais e humanas para o desenvolvimento da vida em sociedade se davam no próprio território. Com o desaparecimento gradual deste contexto histórico e a internacionalização dos aspectos mais básicos de manutenção da vida, como a alimentação, os distritos adquiriram características globais. Assim, a definição de ações em saúde pública não pode basear-se apenas nas características territoriais dos distritos, mas sim na soma destas com as características virtuais, originadas das inter-relações entre diversos distritos, regiões e países. É o surgimento do distrito globalizado, virtual, interdependente e sem fronteiras. Mesmo o responsável pela saúde de um distrito necessita pensar e agir globalmente para proteger a saúde dos cidadãos, necessitando tomar decisões com mais liberdade e autonomia frente à pirâmide hierárquica em que muitas vezes se vê aprisionado. O fluxo de informação e decisão dentro das organizações piramidais segue um longo caminho dentro de suas estruturas hierárquicas, o que lentifica o reconhecimento de riscos e obstrui a adaptação e adoção de ações em saúde, verificadas como efetivas em outros distritos. A imobilidade destas instituições impede a aquisição da agilidade necessária, tanto para a análise de dados e tendências da situação de saúde, como para a aplicação das investigações mais recentes e políticas efetivas que, respectivamente, expliquem e incidam sobre as mesmas (Figura 1). Em resumo, a organização dos serviços de saúde pública não está conformada pelos problemas de saúde e suas origens, mas sim pela estrutura do Estado-nação, o que a torna ineficaz.

Além destes fatores e apesar de nos últimos trinta anos a saúde pública ter desenvolvido uma rica tradição de trabalho horizontal, sua dependência do Estado faz com que a ação comunitária, mais cedo ou mais tarde, entre em colisão com os interesses do governo. A autoridade sanitária não reside nos profissionais, mas sim no Estado e seus governantes (Alvarez-Dardet, 2000). Uma das conseqüências desta ambigüidade na hora de eleger entre servir às necessidades da população ou a seus governantes é a crescente perda de confiança das instituições sanitárias frente à opinião pública (Tabela 1). Desta forma, acreditamos que as instituições de saúde pública necessitam adaptar-se às transformações que o processo saúde-doença vem sofrendo, sem implicar em diminuição da responsabilidade social do Estado.
Navarro (2000), através da análise de políticas públicas de defesa do estado de bem-estar em países europeus, demonstra que a internacionalização do comércio não necessariamente implica no abandono de políticas sociais por parte dos estados nacionais. Ao contrário, demonstra, através do exemplo de estados como Suécia e Noruega, que nos períodos de maior internacionalização de suas economias, houve concomitantemente, maior inversão em políticas públicas de caráter social. Desta maneira, pretende negar que as "exigências" da globalização impliquem no abandono de políticas de proteção social. Recentemente, este mesmo autor definiu, através de dados empíricos, a importância das políticas sociais e redistributivas dos estados para se alcançar avanços no nível de saúde da população (Navarro \& Shi, 2001). Mas, mesmo assumindo um estado imaginário comprometido com políticas sociais, verificamos que as transformações atuais na complexa e problemática rede de eventos que envolve comércio, globalização e saúde não possibilitam a este estado dispor de todos os instrumentos necessários para fazer frente aos desafios transnacionais à saúde de sua população (Lang, no prelo). Como afirma Habermas em um recente artigo sobre globalização: “...a perda da autonomia significa, entre outras coisas, que um Estado já não pode por si mesmo proteger adequadamente seus cidadãos frente aos efeitos das decisões que tomam outros atores ou frente aos efeitos subseqüentes dos processos que se originam fora de suas fronteiras..." (Habermas, 2001:5). É neste contexto de internacionalização, perda de fronteiras, globalização epidemiológica e rigidez do modelo piramidal dos serviços de saúde que sugerimos uma alternativa à prática atual de saúde pública. Uma nova forma de ação coletiva transnacional que escape à armadilha das pirâmides, isto é, que não se limite a uma prática local para enfrentar riscos globais. Na prática clínica esta armadilha se manifesta de forma similar. $O$ já citado aumento global na freqüência de resistência farmacológica ao bacilo da tuberculose, exemplifica a necessidade de uma estratégia terapêutica semelhante em distintos países, adaptada a sua realidade local, que leve em consideração tanto a eficácia medicamentosa de um opção terapêutica, como também ações que aumentem a aderência à mesma e a intervenções sobre fatores predisponentes desta infecção, como as condições de habitação, a desnutrição, a AIDS, etc. Para a definição desta estratégia e a contínua monitorização de sua efetividade é necessário ultrapassar certos entraves burocráticos oriundos destas instituições e iniciar 
um trabalho conjunto entre profissionais de saúde e investigadores, unindo as bases das pirâmides e escapando de suas armadilhas.

\section{Um novo modelo de ação}

Este novo modelo reside na própria natureza da globalização. Como já citado anteriormente, a globalização é caracterizada, entre outras coisas, pela velocidade no fluxo de informação entre as pessoas dos mais diversos países. Estes avanços na tecnologia da informação geram a oportunidade de criação de conhecimento global (Garner \& McKee, no prelo), através do acesso a fontes de informação, a estatísticas sobre estado de saúde, a avaliações sobre intervenções sanitárias, a exemplos de boas práticas, ao contato direto entre pares, entre outros. Este acesso democratiza o conhecimento acerca de saúde, tanto entre profissionais de diversos países, como também entre os profissionais e a população. Este maior acesso à informação e conhecimento, pode auxiliar a reduzir as ineqüidades entre indivíduos, classes e países, sempre tendo em mente a necessidade de adaptação deste conhecimento "global" à realidade local (Garner \& McKee, no prelo). Entretanto, dois fatores muito importantes reduzem esta possibilidade de democratização do conhecimento: a restrição ao acesso a sistemas de informação e a privatização do conhecimento através de leis de propriedade intelectual. $\mathrm{O}$ primeiro é determinado pela capacidade econômica dos países, instituições e indivíduos representando um obstáculo à "universalização" de nossa proposta, enquanto o segundo representa um desafio que este novo modelo de ação pode ajudar a vencer.

Neste contexto, surge a proposta de se utilizar as redes como modelo organizativo em saúde pública em lugar das burocracias piramidais. Este conjunto de redes teria o objetivo comum de defesa da saúde e combate às ineqüidades em nível internacional e local. Estruturada através do uso das novas tecnologias de informação, seria uma rede eletrônica de profissionais de saúde pública, com maior independência do poder político institucional, mas com forte perfil de atuação política. Formada por membros independentes através de vínculos horizontais voluntários, com múltiplos líderes, organizados em níveis integrados de ação - subsidiariedade - possibilitaria um fluxo rápido de informações, gerando oportunidades de trabalho conjunto entre profissionais que enfrentam problemas semelhantes em lugares distintos, próximos a origem dos mesmos
Figura 1

A armadilha das pirâmides.

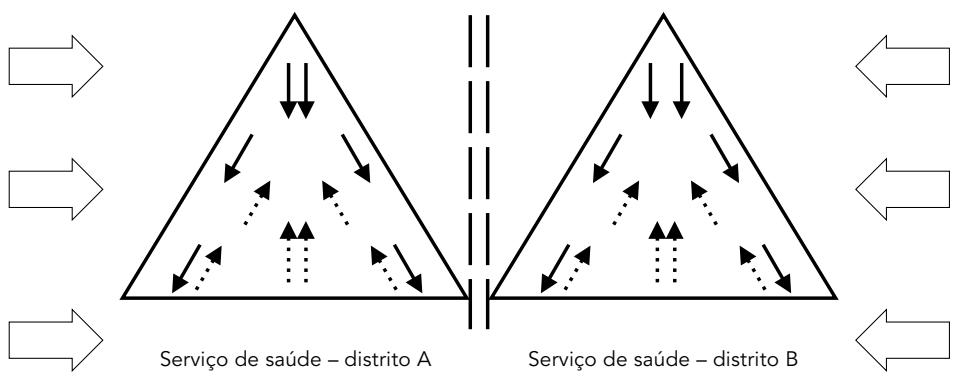
$\longrightarrow$ Determinantes de saúde, riscos, exemplos de boa prática
$\longrightarrow$ Fluxo de decisões
$\cdots$ Fluxo de informações sobre situação de saúde, sobre riscos,
e alternativas de ação

Tabela 1

Características das instituições nacionais

de Saúde Pública.

Origem no Estado-nação do século XIX

Estrutura piramidal

Baseada em área geográfica definida

Autoridade sanitária subordinada ao Estado

Incapaz de lidar com as necessidades da população

Instituição pré-globalização

(Kickbush, 1999). Além da união entre profissionais de saúde pública, possibilitaria o contato entre distintos setores sociais, nos diferentes pontos das diversas redes já existentes. Tomando como exemplo a saúde do trabalhador: no momento da identificação de um problema de contaminação profissional em uma empresa brasileira, o sindicato local poderia ter acesso imediato, através da rede, a experts em saúde do trabalhador, a sindicatos e profissionais de saúde de outro lugar ou país com experiência no problema e às soluções e encaminhamentos realizados com sucesso, tanto no sentido de controlar o risco imediato, como também na criação de lugares de trabalho saudáveis, além da possibilidade de emissão de um alerta global quanto a possível reprodutibilida- 
de do caso. Este exemplo caracteriza duas estratégias complementares de ação, uma abordagem por riscos e outra por ambientes, que, a nosso ver, deveriam guiar a atuação da rede. Ao ser formada por profissionais de saúde pública de todo o mundo, trabalhando individualmente em centros acadêmicos, instituições públicas nacionais, organismos internacionais, etc., teria legitimado forte poder de representatividade, podendo influenciar esferas de decisão nacionais e internacionais na adoção de políticas públicas saudáveis, criando um espaço público global. A comunicação entre pares favoreceria a adaptação de modelos eficazes de boa prática à realidade local, conectando as bases das pirâmides através das estratégias de ação dos protagonistas locais. Esta interação entre o global e o local favoreceria a criação de distritos virtuais, como o espaço de ação dos profissionais de saúde pública. Este processo de "glocalização", onde influências externas transformam a realidade local através de uma reinterpretação própria, favoreceria, também, a expressão do local sobre o global (Tabela 2). Ao permitir a divulgação e o intercâmbio direto de informação e possibilitar a mobilização de profissionais de todo mundo, poderia ser utilizada como ferramenta de socialização do conhecimento. Milio (2001), sugere estratégias de uso da Internet que serviriam como guia de estruturação da rede, definindo uma agenda de ação que inclui a criação de uma base de conhecimento confiável e, entre outros, um marco de coordenação para a defesa da saúde.

\section{Conclusão}

Como cita Kickbusch (1999:451): "A rede surge como o ideal de organização na era da informa-

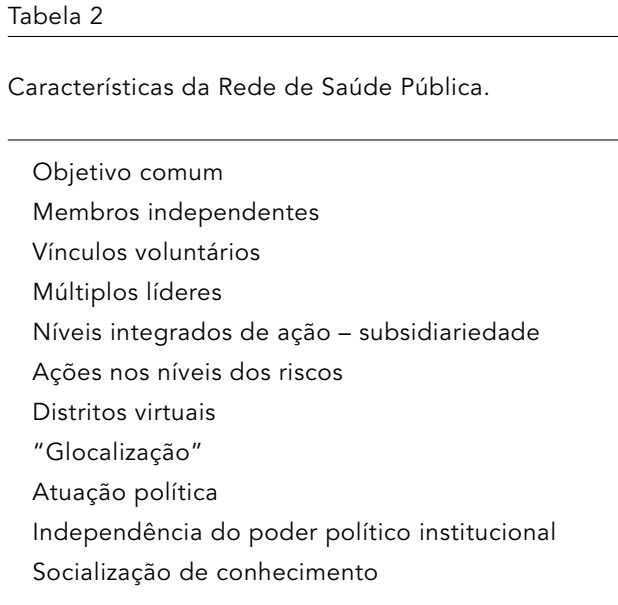

Extraído parcialmente de Kickbusch (1999).

ção, como a burocracia o foi na era industrial, a hierarquia na pré-industrial e os pequenos grupos errantes durante o nomadismo". Esta nova forma de atuação dos profissionais de saúde pública, a rede, não é um evento isolado. Estruturas empresariais, organizações não-governamentais, movimentos sindicais e populares estão se reorganizando em redes em busca de maior poder de ação. A globalização exige novas formas de atuação em nível transnacional e local em defesa da saúde, e a rede parece representar um modelo de organização que possibilita uma maior influência dos profissionais da área neste processo. Pretendemos com nosso artigo, trazer algumas sugestões à sua construção e, principalmente, iniciar este debate, provocar reações e novas aportações. Imaginar e construir coletivamente um espaço virtual-real que possa tornar mais efetivas as ações de saúde pública para a população do planeta. 


\section{Referências}

ALVAREZ-DARDET, C., 2000. La salud pública, el estado y la medicina: ¿Amistades peligrosas? In: Competencias Profesionales en Salud Pública. (Comissió de Salut Pública, Consell Català d'Especialitats en Ciències de la Salut, ed.), pp. 57-66, Barcelona: Institut Universitari de Salut Pública de Catalunya.

BAUM, F., no prelo. Health, Equity, Justice and Globalisation: Some lessons from the People's Health Assembly. Journal of Epidemiology and Community Health.

DATASUS (Departamento de Informática do SUS), 2001. Dados Nacionais Sobre Mortalidade por Distintas Causas no Ano de 1998. 16 Março 2001. <http://www.datasus.gov.br/tabnet/tabnet.htm>.

GARNER, P. \& McKEE, M., no prelo. The way forward. In: International Co-operation in Health (M. McKee, P. Garner \& R. Stott, ed.), Oxford: Oxford University Press.

HABERMAS, J., 2001. El valle de lágrimas de la globalización. Claves de Razón Práctica, 109:4-10.

KICKBUSCH, I., 1999. Global + local = glocal public health. Journal of Epidemiology and Community Health, 53:451-452.

LANG, T., no prelo. Trade, public health and food. In: International Co-operation in Health (M. McKee, P. Garner \& R. Stott, ed.), Oxford: Oxford University Press.

LANG, T. \& CARAHER, M., no prelo. How to influence policy on health and health care at the international level? In: Oxford Handbook of Public Health (D. Pencheon \& D. Melzer, ed.), Oxford: Oxford University Press.
LAURELL, A. S., 2000. Globalización, políticas neoliberales y salud. In: Salud y Equidad: Una Mirada Desde las Ciencias Sociales. (R. Briceño-León, M. C. S. Minayo \& C. A. E. Coimbra Jr., org.), pp. 73 84, Rio de Janeiro: Editora Fiocruz.

LEE, K.; COLLINSON, S.; WALT, G. \& GILSON, L., 1996. Who should be doig what in international health: A confusion of mandates in the United Nations? BMJ, 312:302-307.

MILIO, N., 2001. The internet, public health, and the globalisation of just about everything. Journal of Epidemiology and Community Health, 55:74-76.

NAVARRO, V., 1997. WHO: Where there is no vision, the people perish. Lancet, 350:1480-1481.

NAVARRO, V., 2000. Are pro-welfare state and full-employment policies possible in the era of globalization? Intermational Journal of Health Services, 30:231-251.

NAVARRO, V. \& SHI, L., 2001. The political context of social inequalities and health. Social Science and Medicine, 52:481-491.

UNDP (United Nations Development Programme), 1999. Human Development Report. New York: Oxford University Press/UNDP.

WALT, G., 1998. Globalisation of international health. Lancet, 351:434-437.

WILKINSON, R. G., 1996. Unhealthy Societies: The Afflictions of Inequality. Londres: Routledge. 